\title{
Natural Meat-Like Aroma with Antioxidant Potency Based on Bovine Fat by-product via Millard Reaction
}

\author{
Adel G. Abdel-Razek ${ }^{1}$, El-Shahat H. A. Nashy ${ }^{*}$, Ahmed H. El-Ghorab ${ }^{3,4}$ and \\ Khaled F. El-Massry ${ }^{3,4}$ \\ ${ }^{1}$ Department of Fats and Oils, ${ }^{2}$ Department of Chemistry of Tanning Materials and \\ Leather Technology, ${ }^{3}$ Department of Flavor and Aroma, National Research Centre, \\ Dokki 12622 ,Cairo, Egypt and ${ }^{4}$ Department of Chemistry, Faculty of Science, Aljouf \\ University, Saudi Arabia.
}

\begin{abstract}
7 ATS and fatty acids play a significant role as an influential source of the flavor components. The aim of this study was producing of natural meat like aroma components via the interaction of cysteine with bovine fat by product in two model systems. Gas chromatography (GC) and gas chromatography/mass spectrometry (GC/MS) were used to identify the obtained volatile compounds. Thermal treatment of cysteine/ bovine fat by-product with or without water gave several thiol compounds such as 2-methyl-3-furanthiol, 2-furylmethanethiol and methyl-dihydrofuranthiol. A number of disulfides compounds were formed as 2-methyl-3-furyl2-methyl-3-thienyldisulphide, bis-(2-methyl-3-furyl) disulphide, 2-methyl-3-furyl-methyl2-xopropyldisulphide. Furans and sulfur-containing compounds are important precursors of meaty aromas.

Sensory evaluation of the aroma products was performed for cysteine and bovine fat byproduct model systems according to International Standards Organization (ISO) method. The results revealed that the presence of volatiles having boiled note in presence of water may be due to the preponderance of thiol compounds $(22.33 \%)$ and roasted character attributes to the presence of higher content of pyrazine (1.28\%), 2-methylthiazole $(0.4 \%)$, furfural $(3.0 \%)$ and methylfuraneol (31.47\%). It was found that, the antioxidant activity of model system containing water has higher antioxidant activity $(78.0 \pm 1.8 \%)$, in comparison with tert-butylhydroquinone (TBHQ) $98.73 \pm 2.3 \%$. From the above results, the obtained natural identical meat-like aroma concentrate, could be applied as food additives.
\end{abstract}

Keywords: Meat like aroma, Bovine fat, Millard reaction, Antioxidant activity, Sensory evaluation.

\section{Introduction}

Many studies over several years ago have focused on the flavor and aroma of meat for human consumption in particular beef, which is the most preferable and highly valued meat in many countries [1-7]. Animal fats may affect food flavor in different ways: (I) Fatty-acids, on oxidation, can generate carbonyl components that are capable as a flavor contributor, as well (II) Lipids are original source of flavor ingredient, un-modified and indirectly (modified products). The released volatile components from fats or produced from triacylglycerol or phosphatide fractions may be effective for the certain species bovine or lamb flavors. Fat has the wonderful efficiency to absorb and preserve the flavors. Fats as well include compounds that provide special flavors. Fat may work as store station for odorous compounds that are progressive during the heating process [8-10].

The non-volatile precursors having a low molecular weight, intrinsic for meat flavor, are water-soluble components, like free amino acids (FAAs), peptides, some organic acids, sugars, nucleotides and their metabolites [11-14].

The different flavors of meats depend on different culinary procedures are mainly due to the temperature of the cooking process and the water content of the meat. Subsequently, the flavor of boiled meat is generated in the presence of water at temperatures nearly $100^{\circ} \mathrm{C}$. The

\footnotetext{
${ }^{*}$ Corresponding author e-mail: nashy_eha@yahoo.com DOI: 10.21608/ejchem.2017.1342.1086

C2017 National Information and Documentation Centre (NIDOC)
} 
flavor and aroma of roasted meat, however, are produced at temperatures over $100^{\circ} \mathrm{C}$ in relatively dry conditions [15].

The Maillard reaction (MR) has a major technological importance in the development and imitation of desirable flavors and aromas for processed foods. It has been used in large scale for the manufacture of imitation flavors, particularly meat taste, and its aromas. Most patents proposed for meat flavors creation have involved sulfurcontaining amino acids, usually cysteine [16]. Ohloff and coworkers [17] reported that the meaty aroma is attributed to the prolonged heating of cysteine which found in muscle protein [18].

It is well known that the cooking of meat results in oxidation of fat, which create a pleasant smell [19]. Raw meat emphasizes bland and metallic flavors and little aroma while cooked meat has a characteristic flavor. The precise sensory properties of meat were developed fully after heat treatment and its generation depends on the kind and intensity of cooking time and temperature. Flavor is one of the most critical odors because of its sensorial characteristics. The flavor precursors, when heated, of meat undergo a series of physical and chemical changes that are governed by temperature and water content.

Safety of food flavors has been highly concerned in recent years. So, the consumers around the world are becoming more aware of the nutritional value and safety of their foods and its constituent. In addition, there is a preference for ingredients natural food that is supposed to be safe, healthy and less subjected to hazards than those synthetic counterparts. However, more studies should be introduced in order to achieve an economical final product to meet the consumer's demands especially in the field of meat flavor [20].

The oxidative reactions which may occur in foods can be affected on their sensory and nutritional characteristics. Therefore, compounds having antioxidant potency possess a role for inhibition of the autoxidation. There is renewed more attention to use the natural products due to the expected potential health hazard effect of synthetic antioxidants [21].

The aim of the present work was devoted to maximizing the utilization of the bovine fat

Egypt.J.Chem. 60 , No. 5 (2017) by-product, to produce meat-like aroma, using Millard reaction. Physico-chemical characteristics of bovine fat were investigated. The chemical composition of the treated bovine fat and identification of the resulting volatile compounds model systems was studied using GC and GCMS. Determination of antioxidant activity of the different model systems by using DPPH and $\beta$-carotene assays has been investigated as well.

\section{Materials and Methods}

\section{Materials}

- Chemicals used for different fat analysis from Merk, Germany and BDH, England.

-L-Cysteine (L-Cys), $\beta$-carotene, linoleic acid, 1, 1-diphenyl-2-picrylhydrazyl (DPPH), TBHQ, polyoxyethylene sorbitan monopalmitate (Tween-80), chloroform (99\%) and anhydrous sodium sulfate, methylene chloride (MC), pressurized sealed bottles: with thermal taps and n-alkanes (C6-C24) were obtained from Aldrich and Sigma (Germany).

- Authentic samples of volatile compounds purchased from laboratory chemical suppliers and / or were obtained as gifts from flavor companies.

- Local bovine fat was used for the present study supplied by slaughterhouse, Cairo, Egypt.

\section{Methods \\ Analysis of bovine fat}

Chemical characteristics of bovine fat were analyzed according to the American Oil Chemists Society Methods [22]. Acid value, peroxide value, saponification value, iodine value and unsaponifiable matters were determined.

The ester value was estimated by subtracting the acid value from saponification value (SV-AV).

\section{Fatty acid composition}

Bovine fatty acid methyl esters were prepared according to AOCS Official Method Ce 1 k-07 [23-25]. . Determination of fatty acid composition was performed using Hewlett Packard HP 5890 series II gas chromatography, equipped with flame ionization detector (FID), operated under the following conditions: Detector, flame ionization (FID); column, capillary, $30.0 \mathrm{~m}$ x $530 \mu \mathrm{m}, 1.0$ $\mu \mathrm{m}$ thickness, polyethylene glycol phase (INNO Wax); $\mathrm{N}_{2}$ with flow rate, $15 \mathrm{ml}$ per min with average velocity $89 \mathrm{~cm} / \mathrm{s}(8.2 \mathrm{psi}) ; \mathrm{H}_{2}$ flow rate, $30 \mathrm{ml}$ per min; air flow rate, $300 \mathrm{ml}$ per min; split ratio, 8:1, split flow, $120 \mathrm{ml}$ per min; gas saver, 20 $\mathrm{ml}$ per min. Detector temperature, $280^{\circ} \mathrm{C}$; column 
temperature, $240^{\circ} \mathrm{C}$; injection temperature, $280^{\circ} \mathrm{C}$. Temperature programming starting from $100^{\circ} \mathrm{C}$ to reach a maximum of $240^{\circ} \mathrm{C}$ was used for eluting the fatty acid methyl esters. The identification of peaks was made as compared with chromatograms of standard fatty acids methyl ester (Sigma, USA).

\section{Calculated Oxidizability (Cox) Value:}

The Cox value of the oils was calculated by applying the formula proposed by Fatemi and Hammond [26]:

Cox value $=(1[18: 1 \%]+10.3[18: 2 \%]+21.6[18: 3]) / 100$

\section{Meat-like aroma model systems}

Two reaction mixtures were made up in presence or absence of distillated water; A: fat/ L-Cys/ water, B: fat/ L-Cys/ without water, each mixture containing L-Cys $(1 \mathrm{~m} \mathrm{~mol})$ and bovine fat $(10 \mathrm{~g})$. The reaction mixtures were heated for $30 \mathrm{~min}$ in a $1000 \mathrm{~mL}$ sealed bottle (Merck Ltd.), fitted with an airtight and was then allowed to cool and subjected to the further study.

Extraction of volatile compounds of Maillard reaction model systems

The obtained reaction mixtures were subjected to a simultaneous steam distillation (1 L of water) and solvent (MC, $200 \mathrm{~mL}$ ) extraction. The dichloromethane extract was dried over anhydrous sodium sulfate. After the solvent was removed by rotary evaporator, the obtained concentrates were analyzed using GC and GC/ MS according to the method reported by Wettasinghe [27].

Gas chromatography/ (Gas chromatography Mass Spectrometric) analysis

The obtained volatile samples were thermally desorbed, using a modified injector port, directly on the front of a (DB5) $(60 \mathrm{~m} \times 0.32 \mathrm{~mm}$ i.d) fused silica capillary column, in the oven of a PerkinElmer XL gas chromatography and temperature increase from $40{ }^{\circ} \mathrm{C}$ to $240{ }^{\circ} \mathrm{C}$ by the rate $2{ }^{\circ} \mathrm{C} /$ min. Kovat's indices were determined by coinjection of the sample with a solution containing homologous series of n-hydrocarbons $\left(\mathrm{C}_{6}-\mathrm{C}_{26}\right)$ under the same conditions as described above. The separated components were identified by matching with NIST mass-spectral library data, and by comparison of Kovat's indices with those of authentic components and with published data. GC/MS analysis of the two model systems was performed on HP model $6890 \mathrm{GC}$ interfaced to HP 5791A mass selective detector (GC/ MS) was used for mass spectral identification of the
GC components at (MS) ionization voltage of 70 eV. A $30 \mathrm{~m}$ x $0.25 \mathrm{~mm}$ i.d. (DF $=0.25 \mathrm{~lm}$ ) DB5 bonded-phase fused-silica capillary column was used for $(\mathrm{GC})$. The linear velocity of the helium carrier gas was $30 \mathrm{~cm} / \mathrm{s}$. The injector and the detector temperatures were $250{ }^{\circ} \mathrm{C}$. The oven temperature was programmed from 40 to $240{ }^{\circ} \mathrm{C}$ at $2{ }^{\circ} \mathrm{C} / \mathrm{min}$. the quantitative determination was carried based on peak area integration.

\section{Antioxidant activity of Maillard reaction products (MRPs) \\ $\beta$ - Carotene bleaching assay}

Antioxidant activity of the aqueous solution was determined by a $\beta$-carotene/ linoleic acid system [28]. Two $\mathrm{ml}$ of $\beta$-carotene solution $(5 \mathrm{mg}$ $/ \mathrm{ml}$ ) and $40 \mathrm{mg}$ of linoleic acid were transferred to a round-bottom flask. Chloroform was evaporated using a stream of nitrogen, after that, $100 \mathrm{ml}$ of oxygenated distilled water were added slowly to the residue and vigorously agitated to give a stable emulsion. Aliquots of $2 \mathrm{ml}$ of this emulsion with different volumes of the MRP concentrates were added. The same procedure was carried out with standard antioxidant (TBHQ). Absorbance was measured spectrophotometrically at $470 \mathrm{~nm}$ by using (UV-Visible spectrophotometer-Shimadzu, Japan) after incubating the reaction mixtures in water bath $\left(50{ }^{\circ} \mathrm{C}\right)$ and the readings were taken from zero time till $120 \mathrm{~min}$. Antioxidant activity (AA) was calculated as follow.

$$
A \cdot A=\left[1-\left(A_{S_{(0)}-} A_{S_{(120}}\right) / A_{b(0)}-\mathbf{A}_{b(120)} \mid x 100\right.
$$

\section{A. A: Antioxidant Activity}

Where, $A_{S(0)}$ is absorbance of sample at $0 \mathrm{~min}$. $A_{S(120):}$ is absorbance of sample at $120 \mathrm{~min}$ $\mathrm{A}_{\mathrm{b}(0)}$ : is absorbance of control at $0 \mathrm{~min}$. $\mathrm{A}_{\mathrm{b}(120)}$ : is absorbance of control at $120 \mathrm{~min}$.

\section{$D P P H$ free radical scavenging assay}

DPPH free radical scavenging assay was carried out [29]. The various volumes of reaction mixture (MRPs, 50, 100, 200 and $400 \mu \mathrm{l}$ ) were added to $4 \mathrm{ml}$ of DPPH solution $(5 \mathrm{mg} / 500 \mathrm{ml} \mathrm{MeOH})$ and the tubes vigorously shaken and incubated in the dark at room temperature for $30 \mathrm{~min}$. After incubation, the absorbance of the reaction mixture was measured spectrophotometrically at $517 \mathrm{~nm}$. All experiments were carried out in triplicate. The scavenging effect of DPPH free radical was calculated by using the following equation.

Inhibition \% $=\left[\left(A_{B}-A_{A}\right) / A_{B}\right] \times 100$ 
Where:

$$
\begin{aligned}
& A_{B} \text { : absorption of blank } \\
& A_{A} \text { : absorption of sample }
\end{aligned}
$$

Sensory evaluation of meat-like model systems

The sensory analysis was carried out under the conditions specified by ISO method; guidelines after ISO 6658-1985; unstructured graphical scales (ISO 4121-2003) were presented as straight lines $100 \mathrm{~mm}$ long, provided with descriptions on either end. The sensory profile was based on free choice profiling and the following descriptors were retained (out of 32 collected descriptors): 1 $=$ roasted, bread crust, roasted peanuts; 2 = burnt, caramel, bitter; 3 = like- boiled meat; $4=$ likeroasted meat; $5=$ spicy, sulphury, onion, garlic; 6 = sharp, pun get, burning; 7 = earthy, musty, moldy, sweat, $8=$ malty, sweet; $9=$ solvents, synthetic, chemicals; 10 = others-specify which); in the profile evaluation: $0 \mathrm{~mm}=$ absent, $100 \mathrm{~mm}$ $=$ very strong. Odor profiles were tested [30].

\section{Statistical analysis}

The obtained results were recorded as means \pm standard deviations and analyzed by SPSS (version 10.1 for windows 98, SPPS Inc.). All analyses were performed in triplicate. Oneway analysis of variance (ANOVA) and Turkey multiple comparisons were carried out to test for any significant differences between the means; the mean value of antioxidant activities and sensory evaluation of model systems.

\section{Results and Discussion}

Bovine fat is a by-product resulting from the meat processing industry (slaughter house) which would have caused environmental problems unless it's used. Such by-products are serious environmental load unless it is modified or utilized as intermediates components in other industries. Consequently, the overall economic return from such by-products would be attractive.

\section{Analysis of fat}

\section{A.Proximate analysis}

The proximate analysis ( $\mathrm{PV}, \mathrm{AV}, \mathrm{SV}$, unsap. and ester values) of the extracted bovine fat were investigated (Table1).

From Table 1 it was found that, SV $192.93 \mathrm{mg} \mathrm{KOH} / \mathrm{g}$ oil. Also, it was noticed that PV, AV and unsap., values are $2.1 \mathrm{~m} \mathrm{Eq} / \mathrm{kg}, 1.31 \mathrm{mg} / \mathrm{g}$ and $0.35 \%$, respectively. Ester value (SV-AV) was $191.62 \mathrm{mg} \mathrm{KOH} \mathrm{/} \mathrm{g} \mathrm{oil.}$
TABLE 1. Chemical properties of bovine fat.

\begin{tabular}{|l|c|}
\hline Properties & Bovine fat \\
\hline Acid value, mg KOH/g oil & 1.31 \\
\hline Peroxide value m Eq/Kg & 2.10 \\
\hline Saponification value, mg KOH/g oil & 192.93 \\
\hline Ester value (S.V.-A.V.) mg KOH/g oil & 191.62 \\
\hline Unsaponifiable matter (\%) & 0.35 \\
\hline
\end{tabular}

\section{B. Composition of fatty acids}

It's clear from Table 2 that, the saturated (SFA) and unsaturated fatty acids (USFA) contents are $56.2 \%$ and $43.8 \%$ respectively. In addition, it was observed that, SFA: USFA ratio is (1.28). Palmitic acid content more than $51.0 \%$ of the SF, while oleic acid represents more than $90.0 \%$ of the USFA. Furthermore, stearic acid makes more than $19.0 \%$ of the total bovine fatty acid composition.

With regard to the total fatty acids present in bovine fats are consists of SFA/ USFA. From the study conducted by Kosowska et al., [8], which interpreted that the oxidation of USFA typically produces a variety of volatile compounds, some of which give the characteristic odors to specific types of meat.

TABLE 2. Fatty acids composition of bovine fat.

\begin{tabular}{|l|c|}
\hline Fatty acids $(\%)$ & Bovine Fat \\
\hline \multicolumn{2}{|c|}{ Saturated fatty acids: } \\
\hline Lauric $\left(\mathrm{C}_{12: 0}\right)$ & 02.1 \\
\hline Myristic $\left(\mathrm{C}_{14: 0}\right)$ & 05.5 \\
\hline Palmitic $\left(\mathrm{C}_{16: 0}\right)$ & 28.7 \\
\hline Stearic $\left(\mathrm{C}_{18: 0}\right)$ & 19.3 \\
\hline Arachidic $\left(\mathrm{C}_{20: 0}\right)$ & 01.6 \\
\hline$\Sigma$ Saturated Fatty Acids & 56.2 \\
\hline \multicolumn{2}{|c|}{ Unsaturated fatty acids: } \\
\hline Palmetoleic $\left(\mathrm{C}_{16: 1}\right)$ & 01.7 \\
\hline Oleic $\left(\mathrm{C}_{18: 1}\right)$ & 39.6 \\
\hline Linoleic $\left(\mathrm{C}_{18: 2}\right)$ & 02.5 \\
\hline$\Sigma$ Un-Saturated Fatty Acids & 43.8 \\
\hline SFA /PUFA & 1.28 \\
\hline Cox Value & 0.654 \\
\hline
\end{tabular}


It is worthy to mention that the Cox value and SFA/PUFA ratio were considered as criteria for fatty materials susceptibility to oxidation [26, 31]. Increasing the content of SFA (palmitic \& stearic) and monounsaturated fatty acids (MUFA) have a positive influence on the ratio of SFA/ PUFA as well as Cox value oxidative stability [32]. Generally, a low content of PUFA (linoleic acid) and absence of linolenic acid in addition to the increasing of MUFA leads to prolonging the oxidative stability.

Meat- like aroma via Maillard reaction

The Maillard reaction has been widely used for aroma generation. Since it has a powerful effect on the outside appearance, flavor and nutritional characteristics for different foodstuffs. MR is a chemical reaction between reducing compounds (as carbonyl compounds) and amino acids and chiefly responsible for the development of aroma and taste during food processing. The primary reactions in cooked meat are the oxidation of lipids lead to the formation of aroma compounds, moreover, high temperature can help the oxidation of USFA [33].

In this study, the cysteine was chosen as amino acid and bovine fat as carbonyl source in model systems to prepare meaty aroma as well as determine the antioxidant activity of two model systems. Thermal reaction of cysteine produced aldehyde, hydrogen sulfide and ammonia, Scheme (1).

The reaction between the produce hydrogen sulfide and ammonia with the generated volatile components which formed from the thermal oxidation of fat has been represented in schemes (2-5). The heterocyclic compounds, particularly those containing sulfur and/or nitrogen are very significant as a precursor for meat-like aroma production.

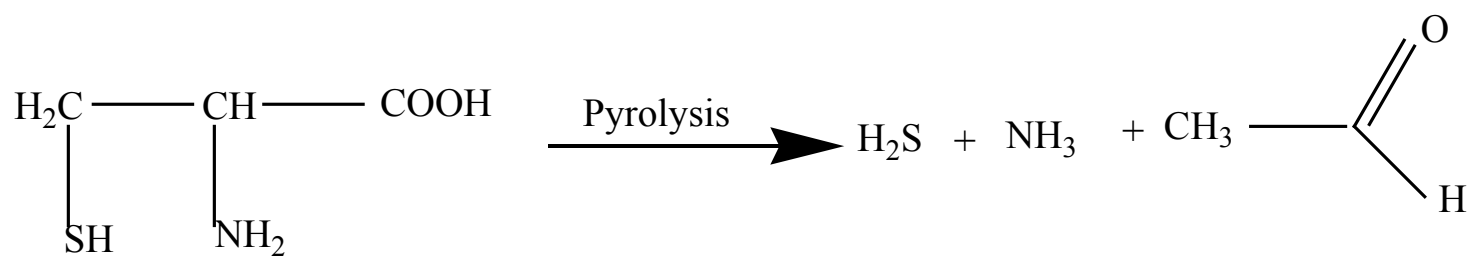

Cysteine

Scheme 1. Pyrolysis of cysteine.

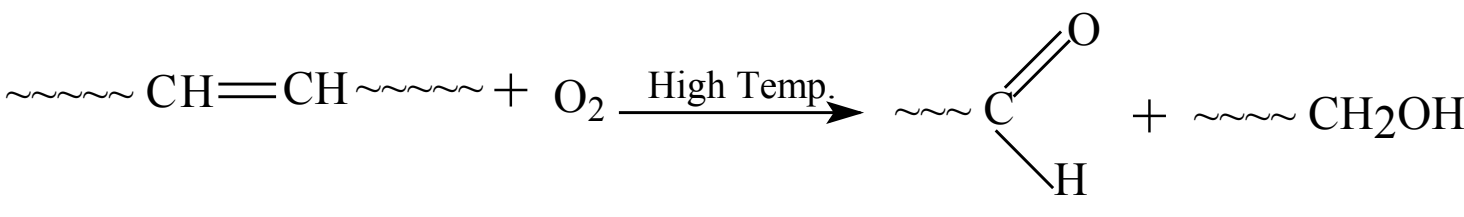

Aldehyde

Alcohol<smiles>[R]C(=CC)CC[O+]C1CC1</smiles><smiles>CC=O</smiles>

Aldehyde<smiles>[R]C([3H])=O</smiles>

Ketone

Scheme 2. The representative oxidation reactions of fat 


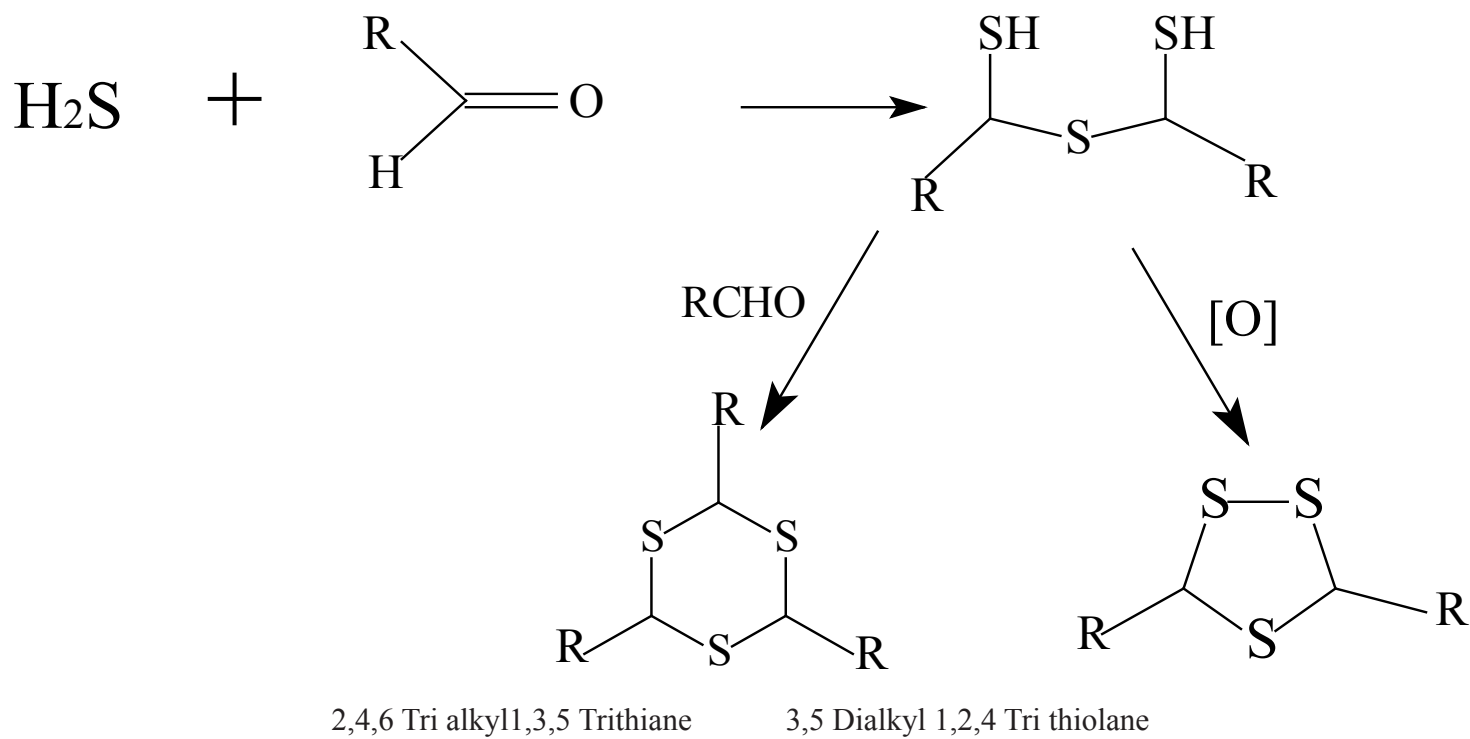

Scheme 3. Representative route for the formation of some sulfur heterocyclic compounds (thiane and thiolane) formed from milliared reaction (protein-fat).

$\mathbf{R}_{1}$<smiles>CC=O</smiles>
$\mathrm{NH}_{3}$<smiles>C=CC</smiles><smiles>C=[OH+]</smiles><smiles>[R]C(N)O</smiles><smiles>CC(=O)C(C)=O</smiles><smiles>[R]C(O)/N=C(/C)C(C)=O</smiles><smiles>[R1]C1N=C(C)C(C)(O)S1</smiles><smiles>[13SH2]</smiles>

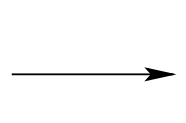<smiles>[R]C(O)/N=C(/C)C(C)(O)S</smiles><smiles>CO</smiles><smiles>[R]c1nc(C)c(C)s1</smiles>

2,4,5 Tri alkyl -1,3 Thiazole

Scheme 4. Representative route for the formation of sulfur and nitrogen heterocyclic compounds (thiazoles) formed from maillard reaction (protein-fat). 


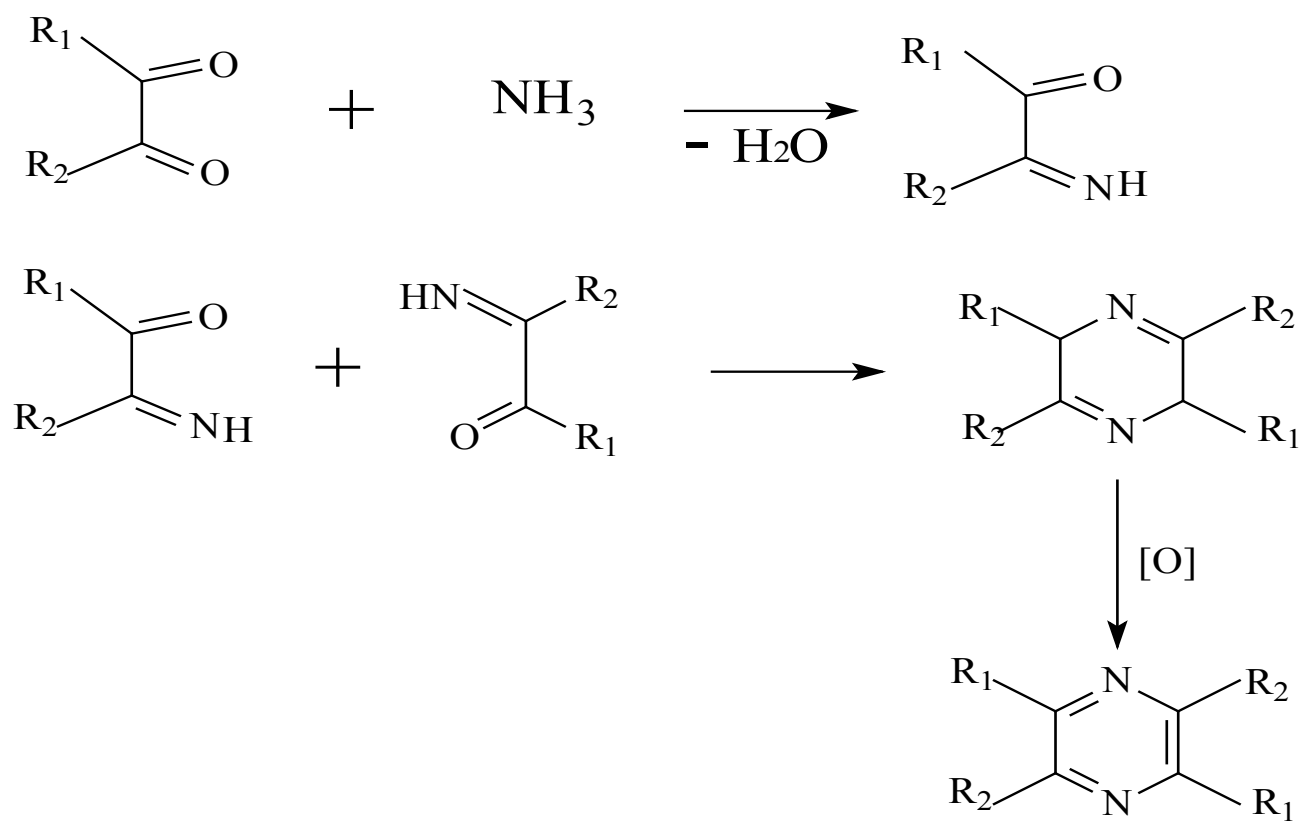

Scheme 5. Representative Route for the Formation of some Nitrogen Heterocyclic Compounds (pyrazoles) formed from Maillard Reaction (Protein-Fat).

Gas chromatographic analysis of meat-like aroma model systems

The volatile aldehydes and ketones compounds produced by the thermal oxidation are the main aroma substances derived from bovine fat oxidation. The identified volatile compounds were shown in Table (3). Thirty-five and twentyfour volatile compounds were recorded in fat/ cysteine with or without water model systems A and $\mathrm{B}$ respectively, including aliphatic aldehydes, ketones, thiophenes, aliphatic alcohols, oxygen, nitrogen and sulfur containing compounds.

\section{Carbonyl compounds}

Short chain aldehydes, ketones and bicarbonylic precursors were identified in the two model systems (A and B) with (16.40 and $11.53 \%)$, respectively, Table (3).

a. Aldehydes: The identified aldehydes and ketones in model systems (A \& B) were shown in Table (3), 3, 6-nonadienal was the most abundant aldehydes in (A and B) model systems, while tridecanal was generated in (A) model system only with $(0.64 \%)$. As illustrated in Table (3), the most obtained aldehydes are straight chain this due to the thermal oxidation of USFA, which is agreement with that previously reported [34]. It was observed that, the system conditions effect on fat oxidation products. Where, the volatile products of MR in presence of water differ greatly from those in absence of water. The role of moisture in the oxidation of fat indicates that the oxidation decreases with decreasing water content due to the efficiency of water content to manage reactants and catalysts may be significant. The results obtained are in agreement with that obtained by Mottram and Whitfield [35]. The aqueous system plays a leading role in the amount and type of fat oxidation products. Whereas, the impact of water activity refers to its hydrogen bonding between fat hydroperoxides and reaction with free radical oxidation intermediates [35].

b. Ketones: 2-octanone was detected in the model system (A) only with $(0.55 \%)$, which may be attributed due to the thermal degradation of fat in the presence of water. The presence of other short-chain ketones e.g. 2-butanone in (A and B) model systems with $(0.37,5.91 \%)$, respectively can be explained by MR or Strecker degradation (SD) of cysteine. However, the formation of longchain ketones such as trimethyl phenyl butenone $(\mathrm{A}=0.07 \%, \mathrm{~B}=0.1 \%)$ and 2-heptanone $(\mathrm{A}=$ $24.13 \%, \mathrm{~B}=5.51 \%$ ) could be formed due to the condensation between other carbonyl products that derived from fat oxidation. 
TABLE 3. Volatile compounds of a and b model systems.

\begin{tabular}{|c|c|c|c|c|c|}
\hline Peak No. & Compound name & K.I & $\mathbf{A}$ & B & $\begin{array}{l}\text { Method of } \\
\text { Identification }\end{array}$ \\
\hline & \multicolumn{5}{|l|}{ Carbonyls } \\
\hline$\underline{1}$ & 2- Butanone & 604 & 0.37 & 5.91 & K.I \\
\hline$\underline{2}$ & 2,3-pentadion & 726 & 1.8 & 3.0 & K.I \\
\hline$\underline{3}$ & 3-mercapto-2-butanone & 790 & 0.81 & 0.1 & K.I \\
\hline$\underline{4}$ & 2-Heptanone & 886 & 24.13 & 5.15 & K.I \&MS \\
\hline$\underline{5}$ & mercaptomethylpentanone & 940 & 11.66 & 1.82 & K.I \\
\hline$\underline{6}$ & 2-octanone & 991 & 0.55 & nd & K.I \&MS \\
\hline$\underline{7}$ & trimethylphenylbutenone & 1942 & 0.07 & 0.1 & KI \\
\hline$\underline{8}$ & 3,6-nonadienal & 1075 & 0.50 & 0.6 & K.I \\
\hline \multirow[t]{2}{*}{$\underline{9}$} & tridecanal & 1526 & 0.64 & nd & K.I \\
\hline & \multicolumn{5}{|l|}{ Alcohols } \\
\hline$\underline{10}$ & methylbutenol & 624 & 4.43 & nd & K.I \&MS \\
\hline$\underline{11}$ & 1-Heptanol & 883 & 0.68 & nd & K.I \\
\hline$\underline{12}$ & 3-mercapto-2-pentanol & 897 & 2.39 & nd & K.I \&MS \\
\hline$\underline{13}$ & 2-dodecanol & 1467 & 1.34 & nd & K.I \\
\hline$\underline{14}$ & 3-mercaptohexanol & 1531 & 0.45 & 1.8 & K.I \&MS \\
\hline \multirow[t]{2}{*}{$\underline{15}$} & hexadecsanol & 1858 & 0.92 & nd & K.I \\
\hline & \multicolumn{5}{|l|}{$\underline{\text { Esters }}$} \\
\hline \multirow[t]{2}{*}{$\underline{16}$} & Ethylhexadecanoate & 1905 & 0.1 & 0.08 & $\mathrm{KI}$ \\
\hline & \multicolumn{5}{|c|}{ Furan and sulphur containing compounds } \\
\hline$\underline{17}$ & 2-furfural & 814 & 2.58 & 3.0 & K.I \&MS \\
\hline$\underline{18}$ & methylfuraneol & 1760 & 5.33 & 31.47 & K.I \\
\hline$\underline{19}$ & 2-methylthiazole & 826 & 0.4 & nd & K.I \\
\hline$\underline{20}$ & 3-ethylthiophene & 872 & 0.59 & 0.03 & K.I \&MS \\
\hline$\underline{21}$ & 3-merecaptothiophene & 961 & 1.8 & 0.3 & K.I \&MS \\
\hline$\underline{22}$ & 2-methyl-3-furanthiol & 870 & 3.47 & 1.63 & K.I \\
\hline$\underline{23}$ & 2-furylmethanethiol & 906 & 1.0 & 0.04 & K.I \&MS \\
\hline$\underline{24}$ & methyldihydrofuranthiol & 935 & 0.75 & 0.28 & K.I \\
\hline$\underline{25}$ & 1,3-dithiane & 1030 & 0.31 & nd & K.I \&MS \\
\hline$\underline{26}$ & 3-methyl-1,2-dithiolan-4-one & 1071 & 4.18 & 13.03 & K.I \&MS \\
\hline$\underline{27}$ & 1,2,4,5-tetrathiane & 1325 & 2.26 & 1.2 & K.I \\
\hline$\underline{28}$ & 3,4,6-trimethyl-1,2,3-trithiane & 1499 & 0.24 & 2.0 & K.I \\
\hline$\underline{29}$ & 2-ethylthienothiophene & 1430 & 2.75 & 0.6 & K.I \&MS \\
\hline$\underline{30}$ & dihydrothienothiophene & 1290 & 2.64 & nd & K.I \&MS \\
\hline$\underline{31}$ & Bis-(2-methyl-3-furyl)disulphide & 1541 & 0.31 & 1.6 & K.I \\
\hline$\underline{32}$ & $\begin{array}{l}\text { 2-methyl-3-furyl-methyl-2- } \\
\text { oxopropyldisulphide }\end{array}$ & 1596 & 0.1 & 0.12 & K.I \&MS \\
\hline \multirow[t]{2}{*}{$\underline{33}$} & $\begin{array}{l}\text { 2-methyl-3-furyl-2-methyl-3- } \\
\text { thienyldisulphide }\end{array}$ & 1740 & 0.62 & 7.72 & K.I \&MS \\
\hline & \multicolumn{5}{|l|}{ Nitrogen -containing compounds } \\
\hline$\underline{34}$ & Pyrazine & 747 & 1.28 & nd & K.I \&MS \\
\hline$\underline{35}$ & 2-acetylpyrrole & 926 & 0.72 & 0.2 & K.I \&MS \\
\hline
\end{tabular}


c. Dicarbonyls : 2, 3-pentanedione was detected in both model systems (A and B) with $1.8 \%$ and $3.0 \%$ which can be an important intermediate compound in the formation of other volatile products, as thiophenes, thiazoles and poly-sulfur volatiles [36], as shown in scheme (3-5). Where, dicarbonyl compound leads to the formation of mercapto ketones, when react with hydrogen sulphide, as 3-mercapto-2-butanone and mercaptomethyl pentanone with $(0.81,0.1$ 11.66 , and $1.82 \%$ ) in model systems (A and B), respectively. These mercapto ketones and sulfur compounds can produce important meat-like volatiles.

The characterized meaty flavor of model system (A) in comparison with model system (B) due to the presence of mercaptoketones, which contribute to increase the meatiness of meat flavor [36].

\section{Alcohols}

Alcohols derived mainly from thermal decomposition of fat. Different alcohols were detected in model system (A) only. In this study methyl butenol, 1-heptanol, 2-dodecanol and hexadecsanol were identified $(4.43,0.68,1.34$ and $0.92 \%$ ) respectively. Mercapto alcohol as 3-mercapto-2-pentanol was generated in fat/ cysteine in presence of water $(2.39 \%)$ and it was formed via the reaction of the corresponding alkanols with hydrogen sulphide [30]. While 3-mercaptohexanol was detected in both systems (A\&B) 0.45 and 1.8 respectively.

\section{Esters}

Ethylhexadecanoate $(0.1$ and $0.08 \%)$ was released in fat/ cysteine with and without water model systems, respectively. Also, it's thought that esters have a little impact on uncured meat aroma that was generally related with fruity aroma but known to be associated with meaty flavor [34].

\section{Furan/ sulphur- containing compounds}

2-Furfural $(\mathrm{A}=2.58 \%, \mathrm{~B}=3.0 \%)$ and methylfuraneol ( $\mathrm{A}=5.33 \%, \mathrm{~B}=31.47 \%$ ) were identified in model systems (A and B). Although none of the various furan compounds has been referred to meat-like flavor, they have been considered to contribute to the overall odor of boiled or roasted meaty aroma [17]. In addition, there are three thiol compounds such as 2-methyl-3-furanthiol $(\mathrm{A}=3.47 \%, \mathrm{~B}=1.63 \%)$, 2-furylmethanethiol $\quad(\mathrm{A}=1.0 \%, \quad \mathrm{~B}=0.04 \%)$, methyldihydrofuranthiol $(\mathrm{A}=0.75 \%, \mathrm{~B}=0.28 \%)$.
It is well known that, sulphur-containing furans, thiophenes and disulphides have known to possess strong meaty-like aromas [37]. While 2-methyl3 -furanthiol occurred in cooked boiled model system (A), in large concentration than roasted model system (B) which have characteristics smells like cooked cabbage. 2-furylmethanethiol and methyl dihydro furanthiol were found in the two model systems (A and B). The character impact odor compounds as thiol derivatives have been reported to be important in cooked meaty flavor [38].

The essential components of thiophenes present in meat flavor were identified to be substituted at the 2- or 3-position such as 3-ethylthiophene (A $=0.59 \%, \mathrm{~B}=0.03 \%)$ and 3-mercaptothiophene $(\mathrm{A}=1.8 \%, \mathrm{~B}=0.3 \%) .3$-Mercaptothiophene was identified in (A and B) model systems which could be formed due to the decomposition of ribonucleotides of fats in absence of water and it has a roasted note. The results obtained agreed with that obtained by MacLeod et al., [16]. It has been assuming that these sulphur containing heterocyclic compounds could be generated either from thermal degradation of cysteine [25] through the interaction between carbonyl compound from fat and fatty acid degradation products and sulphur-containing amino acids [38]. However, it has been stated that, 3-mercaptothiophene is the only thiophenes with meaty aroma but other thiophenes have sulphur or green / sweet odor [39-40].

Disulphide compounds have been attributed with the meat-like aroma. The presence of thiolsubstituted furans and thiophenes grant rising to a number of significant disulfides in the reaction mixture of model systems (A and B). Three disulphide derivatives were detected in model systems (A and B) such as 2-methyl-3-furyl-1methyl-2-oxopropyldisulphide $(\mathrm{A}=0.1 \%, \mathrm{~B}=$ $0.12 \%)$, bis- (2-methyl-3-furyl) disulphide ( $\mathrm{A}=$ $0.31 \%, \mathrm{~B}=1.6 \%$ ) and 2-methyl-3-furyl-2-methyl3 -thienyldisulphide $(\mathrm{A}=0.62 \%, \mathrm{~B}=7.72 \%)$. The obtained results of the formation of furyl and thienyl sulphide and disulphides were agreement with that previously reported [41 and 42].

Di-and tetra-sulphur containing five or six membered rings were identified in the (A and $\mathrm{B}$ ) systems, such as 3-methyl-1, 2-dithiolan-4-one (A $=4.18 \%, \mathrm{~B}=13.03 \%)$ and $1,2,4,5$-tetrathiane ( $\mathrm{A}=2.26 \%, \mathrm{~B}=1.2 \%$ ), while 1,3 -dithiane was 
identified in fat/cysteine/water model system with 0.31 [43] described the formation of dithiaolane and aliphatic sulphur compounds via the reaction between the breakdown of fats and cysteine and they are likely to be produced through thermal degradation of cysteine or can be created from the reaction of aldehydes with hydrogen sulphide.

2-Ethylthienothiophene was generated in (A and B) model systems with $(2.75$ and $0.6 \%$ ), respectively, While dihydrothieno-thiophene was detected only in A model system with 2.64\%. Madruga and Mottram [41] reported that a number of alkylthieno-thiophenes were generated in the volatile compounds of cysteine/ ribose model system. In addition, 2-Methyl-thiazole was evolved in model A system only with $0.4 \%$ and this compound was reported in beef cooked at $140^{\circ} \mathrm{C}$.

\section{Nitrogen-containing compounds}

2-acetylpyrrole was identified in model systems (A and B) with $(0.72 \%$ and $0.2 \%)$, respectively, while pyrazine was detected only in the model A (1.28\%). Farmer et al, (44) were reported that 2- acetyl-pyrrol was found in fresh, frozen beef and canned beef, shallow fried beef and it was found in two systems (A and B). The odor of pyrazine has been traditionally regarded as nutty, roasted or burnt. 2-Acetylpyrrol can be formed from the SD that involved due to the interaction of molecules containing nitrogen $(\alpha$-amino acid) with fat degradation products.

\section{Sensory evaluation of (A and B) model systems}

Figures 1 and 2 demonstrate the sensory profiles of (A and B) model systems as well as the intensities of the developed odors and the odor acceptability. Pronounced differences were observed in the odor profiles of (A and B) model systems. As expected, intensities of the roasted, burnt, caramel and sweet notes were weak in (A) models where pyrazine was occurred in low concentration and sulphur derivatives, which were produced from the same bi-carbonylic precursors, occurred in high concentration (Table 3 ). The lower content of furans generated via these model systems is also in agreeable with the lower intensities of the above-mentioned notes due to the presence of more sulphur-derivatives [38].

The boiled like meat aroma was intensive in the volatiles produced through model system (A) due to the preponderance of sulphur-containing compounds. Mottram [40] reported that, boiled meat contains more aliphatic thiols, sulphides as well as heterocyclic compounds with 1, 2 or 3 sulphur atoms in 5- and 6- membered rings, in comparison with model system (B) where the intensities of the roasted, burnt, caramel and sweet notes were strong due to the presence of higher content of pyrazine, thiazole and furfural.

The high content of furans, thiazole and pyrazine is also agreeable with the higher intensities of the above- mentioned notes. Higher intensity of roasted meat note is reasonable, due to the presence of higher content of pyrazine, thiazole and furfural, which were reported previously [43]. While other descriptors gave insignificant results, as the ratings were too low, therefore, they are not included in Fig. 1 and 2.

\section{Antioxidant activity of Maillard model systems (A} and $B$ ).

It is worthy to mention that natural antioxidative components are very respectable for food technology because they prolong the shelf life of fatty foods. Nowadays they are also obtained more interest because it was supposed that, their impact is beneficial for health and they are protective too, e.g. against coronary heart diseases [44]. The radical scavenging activity of the two model systems were measured by DPPH and $\beta$-carotene methods $[29,45,46]$, as clarify in (Fig. $3 \& 4$ ) the model system in entity of water has a high antioxidant potency $(78.1 \%$ at $400 \mu \mathrm{g} /$ $\mathrm{ml}$ ) than fat/ cysteine without water model system $(65.2 \%$ at $400 \mu \mathrm{g} / \mathrm{ml})$ in comparison with the synthetic antioxidant TBHQ $(98.75 \%$ at $400 \mu \mathrm{g} /$ $\mathrm{ml})$. The products of MR concerning to the system in appearance of water was observed to be higher efficacy than that without water may be due to the sharing of phospholipids in model system (A) that, contribute in MR to produce several heterocyclic components having antioxidant potency as sulphides, thiazoles, pyrazines and thiol derivatives [42]. As predictable, model system (A) has higher antioxidative efficiency than the model (B) in the $\beta$-carotene-linoleate method, (A) model system inhibited the bleaching by $(73.6 \%$ at $400 \mu \mathrm{g} / \mathrm{ml})$ compare with TBHQ $(98.88 \%$ at $400 \mu \mathrm{g} / \mathrm{ml})$ (Fig. $3 \& 4)$.

\section{Conclusion}

- This study has proposed a way of converting, previously non-marketable, residual bovine fats to producing meat-like aroma as a value added marketable products. In addition to produce 


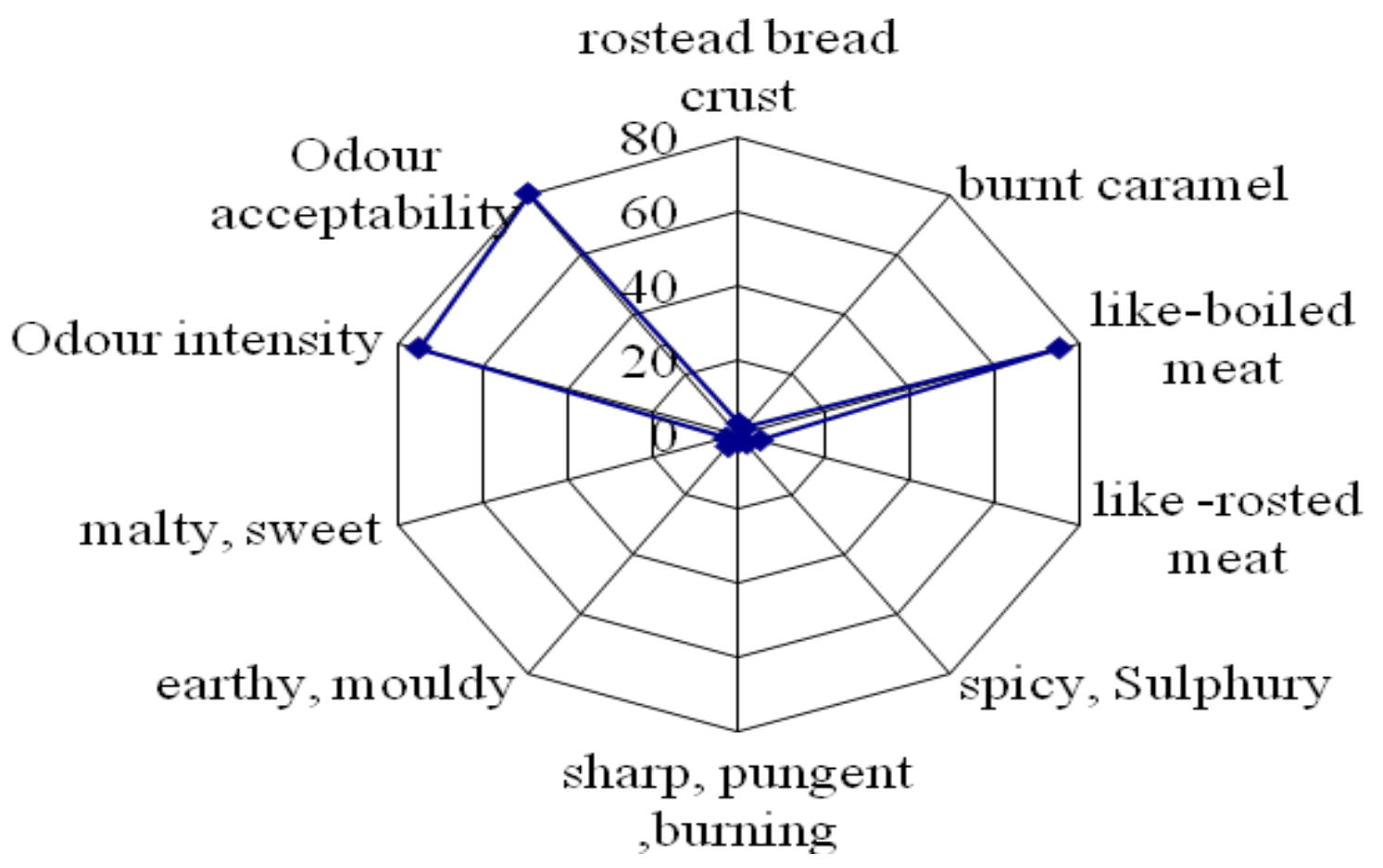

Fig. 1. Aroma profile of A model system.

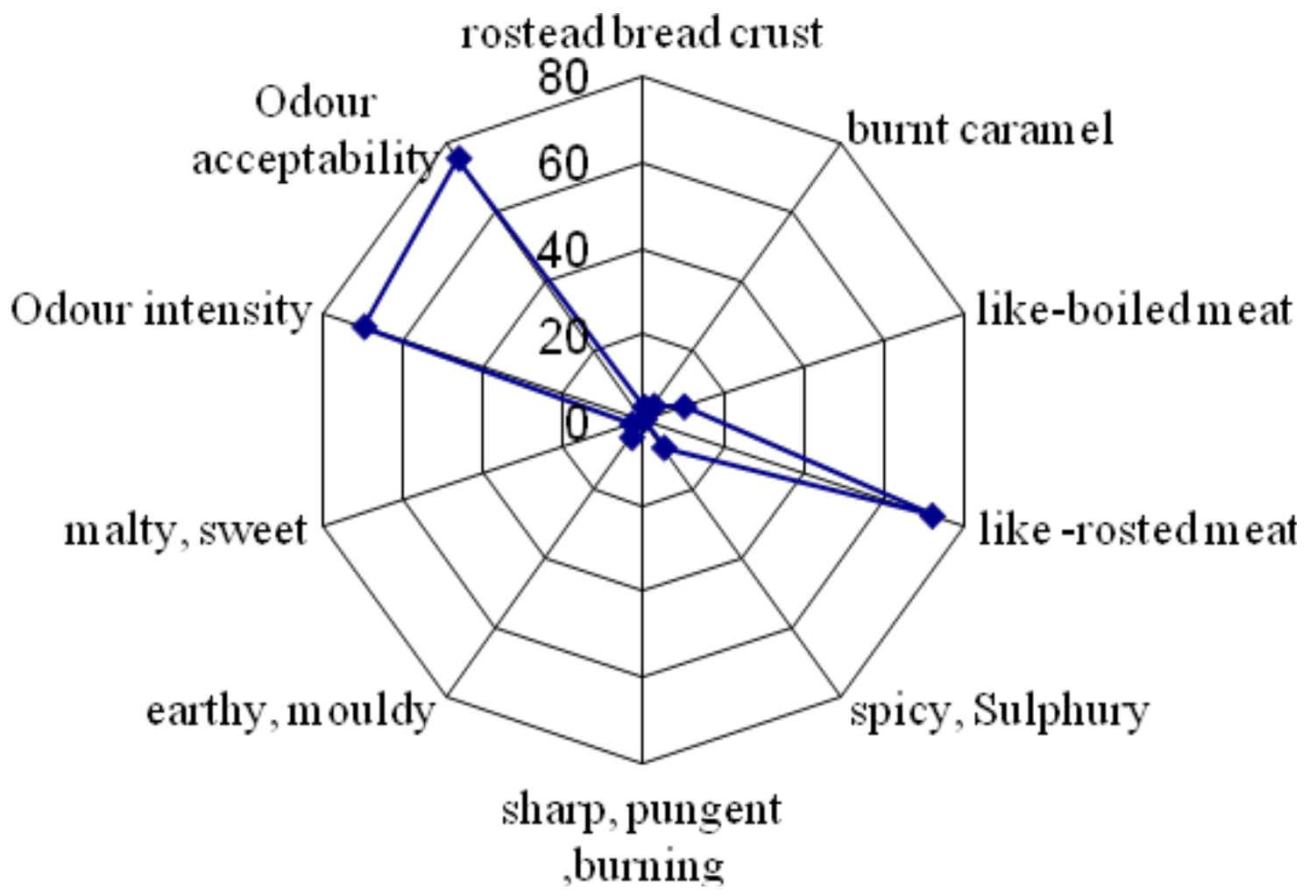

Fig. 2. Aroma profile of B model system. 


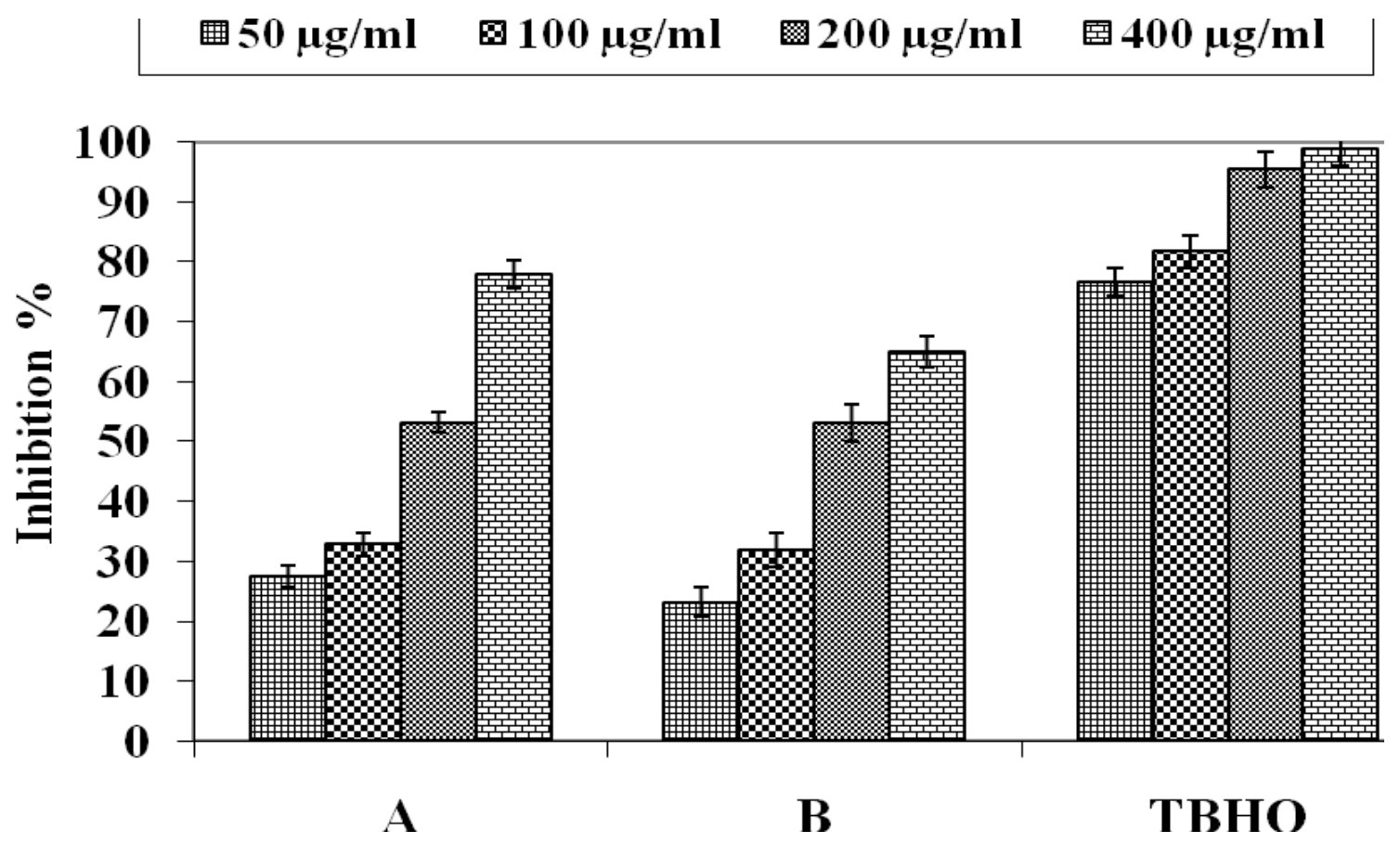

Fig. 3. Antioxidant activity of A and B model systems by dpph method.

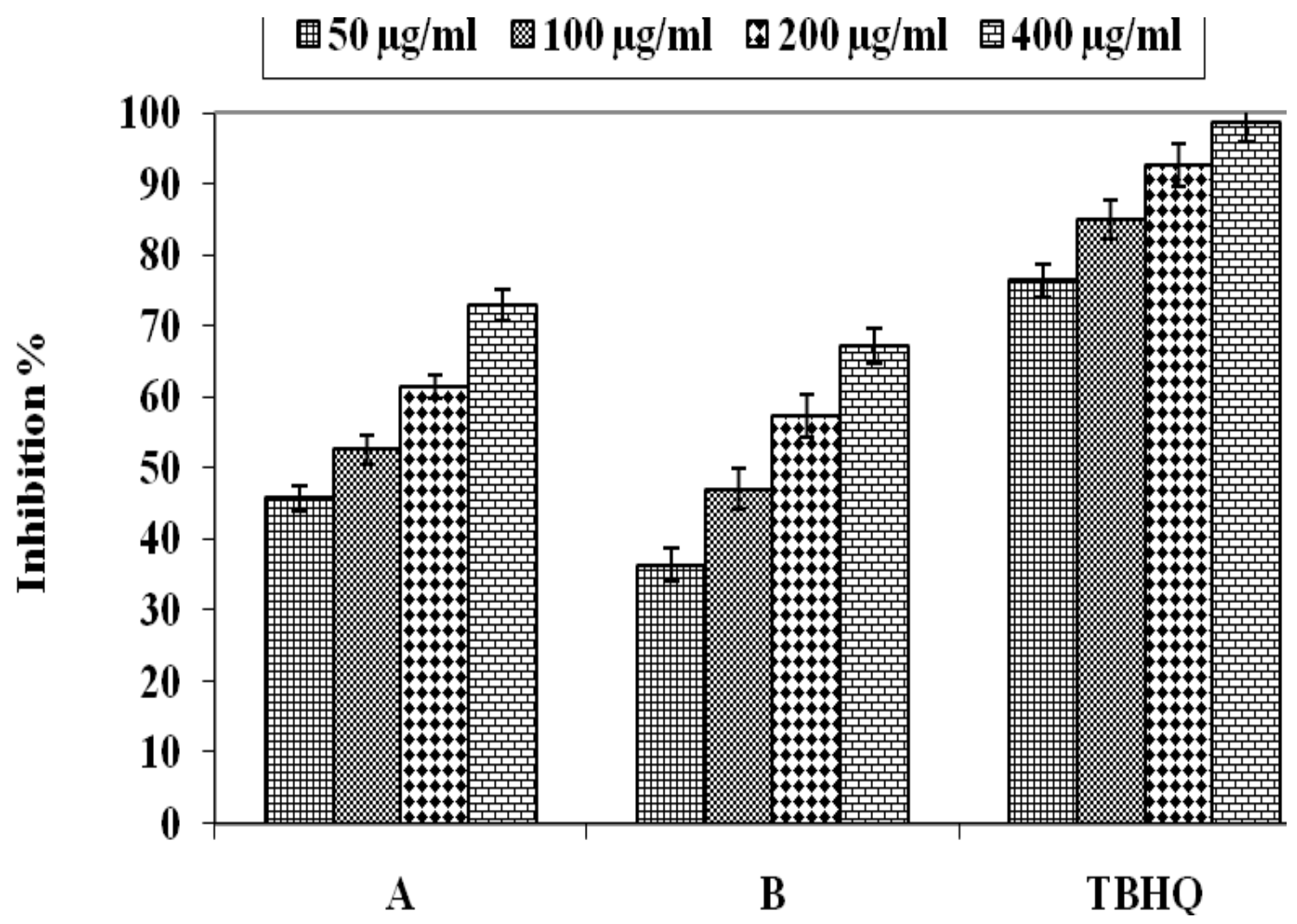

Fig. 4. Antioxidant activity of $A$ and $B$ model systems by $\beta$-carotene method. 
relatively less expensive products based on fat as a natural source of carbonyl groups instead of sugar, through MR.

- The present work indicated that the meatylike flavor consists of a variety of compounds having different aroma prosperities.

- Numerous aroma-active compounds were identified especially sulphur and nitrogen containing compounds as well as (aldehydes, ketones, phenols, organic acids, among others) as responsible for the meat like aroma.

- Bovine fat by-product was used to generated naturally meaty aroma has antioxidant activity and highly sensory evaluation.

- The observed clear result for some classes of compounds to be formed in fat/ cysteine model system in presence of water rather than fat/ cysteine in absence of water such as pyrazine, thiazole, thiophene and disulphide derivatives which are responsible for roasted note while boiled note was attributed to thiol derivatives.

- Recently, new aroma active compounds are still being discovered, and moreover investigations are vital to identify them.

- More studies should be concentrate in reconstitution of the food components, to understand the role of each flavor compound specified in the cooked meat and their possible effect in consumer acceptability.

\section{References}

1. Brunton, N. P., Cronin, D. A. and Monahan, F. J. Volatile components associated with freshly cooked and oxidized off-Flavors in turkey breast meat. Flavor Fragr. J., 17, 327-334 (2002).

2. Reineccius, G. Flavor and aroma chemistry, in Quality Attributes and Their Measurement in Meat, Poultry and Fish Products, Vol 9 of Advances in Meat Research Series, Ed by Pearson AM and Dutson TR. Blackie Academic \& Professional, London, 184-199 (1994).

3. Jayasena D. D., Ahn D. U., Nam K.C. and Jo C. Flavor chemistry of chicken meat: A review. Asian Australas. J. Anim. Sci. 26 (5), 732-742 (2013).

4. Dashdorj D., Tripathi V.K., Cho S., Kim Y. and Hwang I. Dry aging of beef; Review. Journal of Animal Science and Technology. 58, 20 (2016).
5. Mottram, D.S. Some Aspects Of The Chemistry Of Meat Flavor, In Flavor Of Meat And Meat Products, Ed by Shahidi F. Blackie Academic \& Professional, London, 211-230 (1994).

6. Shana L. C., Brúnb A. D., Henchionc M., Lid C., Murrina C., Walla P. G. and Monahan F. J. Consumer evaluations of processed meat products reformulated to be healthier - A conjoint analysis study. Meat Science 131，82-89 (2017).

7. Carmack, C.F., Kastner, C.L., Dikeman, M.E., Schwenke, J.R. and Garcia Zepeda, C.M. Sensory evaluation of beef-Flavor intensity, tenderness and juiciness among major muscles. Meat Sci., 39, 143147 (1995).

8. Kosowska M., Majcher M. A, Fortuna T. Volatile compounds in meat and meat products. Food Sci. Technol., Campinas, 37 (1), 1-7 (2017).

9. Rowe, D. High impact aroma chemicals. Part 2: the good, the bad, and the ugly. Perfumer and Flavorist. 27, 24-29 (2008).

10. Cerny, C. The aroma side of the maillard reaction. Ann. N.Y. Acad. Sci. 1126, 66-71(2008).

11. Imadon, G. I. and Spanier, A.M. Unravelling the secret of meat Flavor. Trends Food Sci. Technol., 5, 315-321 (1994).

12. Spanier, A.M., McMillin, K.W., and Miller, J.A. Enzyme activity levels in beef: effect of postmortem ageing and end-point cooking temperature. J. Food Sci. 55, 318-326 (1990).

13. Ishii, K., Nishimura, T., Okitani A, Tamura Y, Hatae $\mathrm{K}$ and Shimada A. Role of peptides in the taste of cooked beef. J. Home Econ Jpn 46, 307-312 (1995).

14. Tamura, M., Ishii, K., Hatae, K. and Shimada, A. Effect of the peptides fraction in cooked beef on taste. J. Home Econ. Jpn. 48, 607-612 (1997).

15. Manley, C.H. and Ahmedi, S. The development of process flavors. Trends Food Sci. Technol., 6, 4651 (1995).

16. MacLeod, G., and Ames, J.M. Capillary gas chromatography-masspectrometric analysis of cooked beef aroma. J. Food Sci., 51, 1427-1434 (1986).

17. Ohloff, G., Flament, I., Pickenhagen, W. Flavor chemistry (Review). Food Rev. Int., 1, 99-148 (1985).

18. Jayasena D. D., Dong Uk Ahn, Ki Chang Nam and Egypt.J.Chem. 60 , No. 5 (2017) 
Cheorun Jo. Flavor chemistry of chicken meat: A review. Asian Australas. J. Anim. Sci. 26(5), $732-$ 742 May (2013).

19. Belitz, H.D.; Grosch, W.; Schieberle, P. Food Chemistry; Springer: Berlin, Germany, (2009).

20. Sullivan, G.A. Naturally cured meats: Quality, safety, and chemistry. Ph.D Thesis. Iowa State University Ames, Iowa (2011).

21. Wettasinghe, M., Shahidi, F., Amarowicz, R. and Abou-Zaid, M. Phenolic acids in defatted seeds of borage (Borago officinalis L.). Food Chem., 75, 4959 (2001).

22. Davied, F. Official Methods and Recommended Practices of the American Oil Chemists Society, Fifth Edition includes all changes 1993-1997, Edition Analytical methods, Champaigen-Illionois, March. (1998).

23. AOCS. Official Method Ce $1 k-07$, Direct Methylation of Lipids for the Determination of Total Fat, Saturated, cis-Monounsaturated, cis-Polyunsaturated, and trans Fatty Acids by Chromatography. Official Method and Recommended Practices of the American Oil Chemists'Society, 5th ed., American Oil Chemists Society, USA (2007).

24. IUPAC. International Union of Pure and Applied Chemistry. Standard Methods for the Analysis of Oils and Fats and Derivatives, 7th revised and enlarged edn., edited by C. Paquot and A. Haut Fenne, Black Scientific, London (1987).

25. Hassanien M.M.M., Abdel-Razek A. G., Rudzińska M., Siger A., Ratusz K. and Przybylski R. Phytochemical contents and oxidative stability of oils from non-traditional sources. Eur. J. Lipid Sci. Technol., 116, 1563-1571 (2014).

26. Fatemi, S.H., E.G. Hammond. Analysis of oleate, linoleate and inolenate hydroperoxides in oxidized ester mixtures. Lipids, 15, 379-385 (1980).

27. Wettasinghe, M., Shahidi, F., Amarowicz, R. and Abou-Zaid, M. Phenolic acids in defatted seeds of borage (Borago officinalis L.). Food Chem., 75, 4959 (2001).

28. Matthus, B. Antioxidant activity of extracts obtained from residues of different oilseeds. $J$. Agric. Food. Chem., 50, 3444-3452 (2002).

29. Jayathilakan, K. and Sharma, G.K. Role of sugaramino acids interaction products as antioxidants in a methyl linoleate model system. Food Chem., 95, 620-26 (2006).

Egypt.J.Chem. 60 , No. 5 (2017)
30. El-Massry, K., Farouk, A., and El-Gorab, A. Volatile constituents of glutathione/ ribose model system and its antioxidant activity. Amino Acid, 24, 171-177 (2003).

31. Mendez, E., J. Sanhueza, H. Speisky, A. Valenzuela. Validation of the rancimat test for the assessment of the relative stability of fish oils. J. Am. Oil Chem. Soc., 73, 1033-1037 (1996).

32. Abdel-Razek A.G., Hassanein M.M.M., Rudzinska M. and Elmallah M.M.H. Role of minor constituents and balanced fatty acids in upgrading the low stability of cooking oils blended with palm super olein. Asian Journal of Scientific Research. 3 (10), 150-159 (2017).

33. Virginia, C., Resconi, Ana Escudero, and María, M. Campo. The Development of Aromas in Ruminant Meat Molecules. 18, 6748-6781 (2013).

34. Elmore, J. S., Mottram, D. S., Enser, M., and Wood, J.D. Effects of the polyunsaturated fatty acids composition of beef muscle on the profile of aroma volatiles. J. Agric. Food. Chem., 47, 1619-1625 (1999).

35. Mottram, D. S., Whitfield, F.B. Maillard-fat interaction in non-aqueous systems: volatiles from the reaction of cysteine and ribose with phosphatidylcholine. J. Agric. Food Chem., 43, 1302-1306 (1995).

36. MacLeod, G., Seyyedain-Ardebili, M. Natural and simulated meat flavors (with particular reference to beef). Crit. Rev. Food Sci. Nutr., 14, 309- 437 (1981)

37. Ishii, K., Tsuchida, M., Nishimura, T., Okitani, A., Nakagawa, A., Hatae, K. and Shimada, A. Changes in the taste and taste components of beef during heating at a low temperature for a long time. $J$. Home Econ. Jpn., 46, 229-234 (1995).

38. Shahidi, F.; Rubin, L.J. Meat flavor volatiles: A review of the composition, techniques of analysis, and sensory evaluation. CRC Crit. Revs. Food Sci. and Nutri. 24, 141-243 (1986).

39. Guth, H. and Grosch, W. Identification of the character impact odorants of stewed beef juice by instrumental analysis and sensory studies. J. Agric. Food Chem., 42, 2862-2866 (1994).

40. Mottram, D.S. Flavor compounds formed during the Maillard reaction. In Thermally Generated Flavors: Maillard, Microwave, And Extrusion Processes, Parliament, T.H., Morello, M.J., McGorrin, R.J., ACS Symposium Series, 543, ACS: Washington 
DC, 104-126 (1994).

41. Madruga, M.S. and Mottram, D.S. The effect of $\mathrm{pH}$ on the formation of Maillard-derived aroma volatiles using a cooked meat system. J. Sci. Food Agric. 68, 305-310 (1995).

42. El-Ghorab A. H., Khaled, F. El-massry, Atef, F. El-Hadadd, Saeid A. Shedied, Mohamed, S. Shaheen and Gad, M. A. Chemical composition and antiradical activity of the volatile compounds from reaction of cysteine/ ribose and beef fat. World $J$. Dairy and Food Sci., 4 (2), 164-175 (2009).

43. Shu, C.K., and Ho, C.T. Parameter effect on the thermal reaction of cystine and 2, 5- dimethyl-4hydroxy-3(2H)-furanone, In Thermal Generation Of Aromas. Eds. T. H. Parliament, R, J, McGorrin and C.-T. Ho, ACS, Washington, DC, 229-241 (1989).
44. Farmer, L.J. and Patterson, R.L.S. Compounds contributing to meat flavor, Food Chem. 40, 201205 (1991).

45. Adams, R.P. Identification Of Essential Oil Components By Gas Chromatography/ Mass Spectroscopy. Allured Publishing Corporation, USA (1995).

46. Matthus, B. Antioxidant activity of extracts obtained from residues of different oilseeds. $J$. Agric. Food. Chem., 50, 3444-3452 (2002).

(Received 19/7/2017; accepted 17/8/2017)

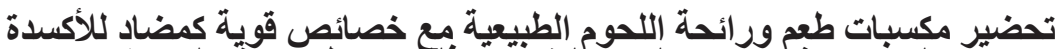

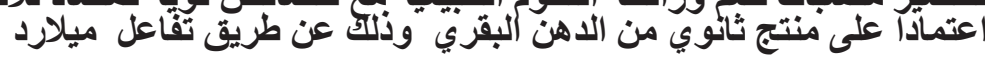

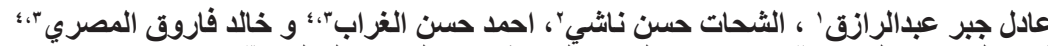

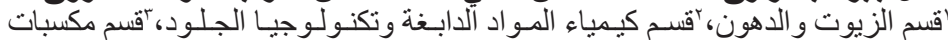

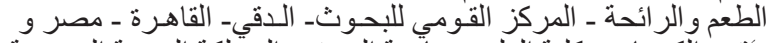

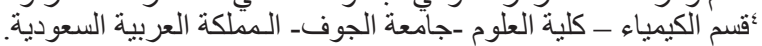

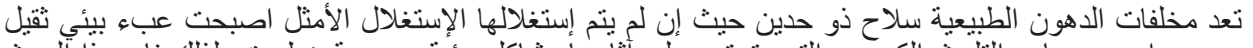

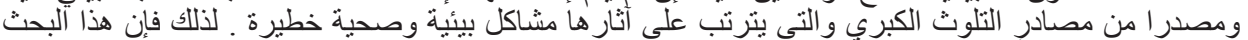

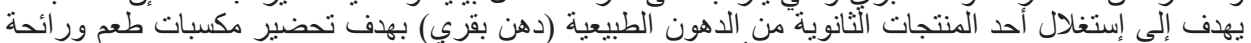

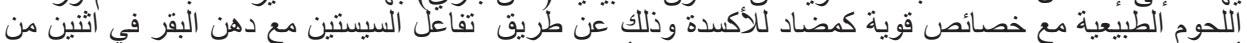

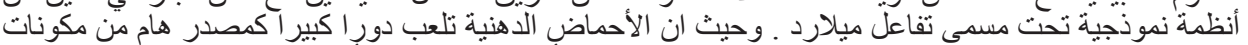

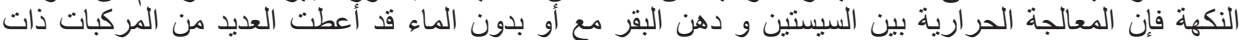

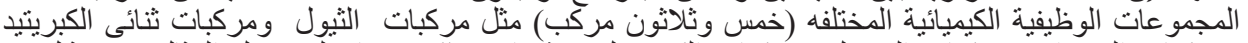

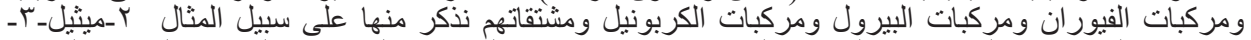

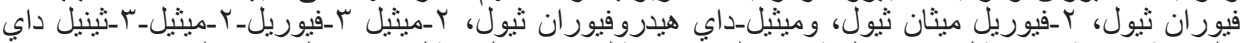

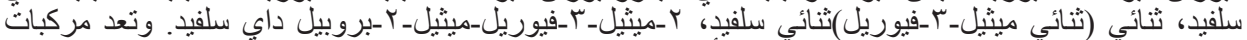

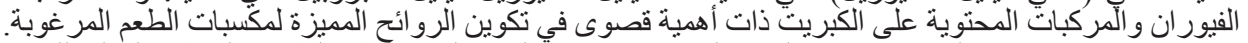

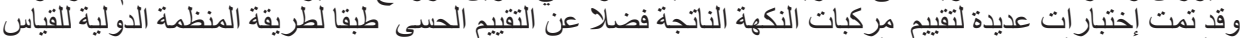

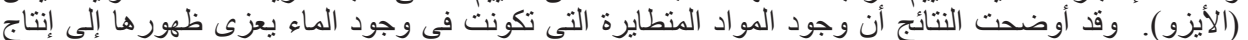

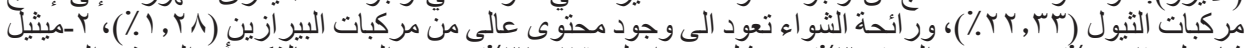

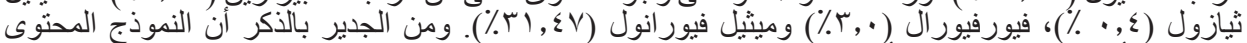

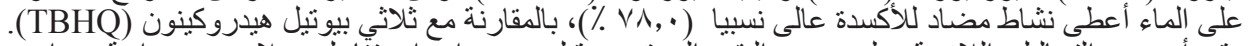

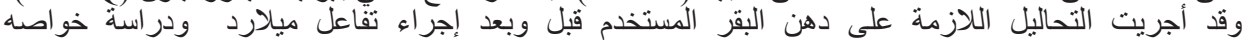

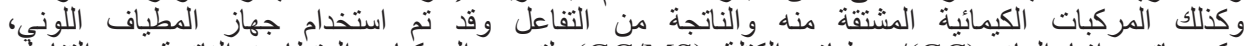

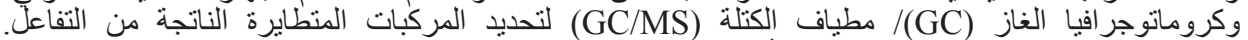

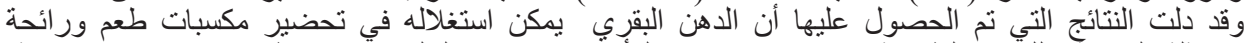

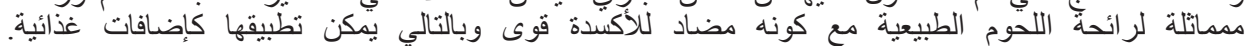

